\title{
Implementasi Penerapan Motivasi Kerja dan Kinerja Karyawan Terhadap Peningkatan Produktifitas Kerja
}

\author{
Nurvi Oktiani ${ }^{1}$, Etika Sabariah ${ }^{2}$, Saridawati $^{3}$, Priska Caroline ${ }^{4}$ \\ 1,2,3,4 Universitas Bina Sarana Informatika \\ e-mail: ${ }^{1}$ nurvi.nvk@bsi.ac.id, ${ }^{2}$ etika.esb@bsi.ac.id, ${ }^{3}$ saridawati.sti@bsi.ac.id, ${ }^{4}$ priska014@gmail.com
}

\begin{tabular}{ccc}
\hline Diterima & Direvisi & Disetujui \\
09-09-2019 & $25-09-2019$ & $27-09-2019$ \\
\hline
\end{tabular}

\begin{abstract}
Abstrak - Peningkatan produktifitas kerja merupakan salah satu tujuan yang sangat penting bagi organisasi dengan adanya peningkatan produktifitas akan memberikan keuntungan bagi organisasi, produktivitas kerja dapat diupayakan dengan pengelolaan organisasi dengan mampu mengadopsi secara positif dari proses penilaian kinerja yang meliputi teknik motivasi untuk meningkatkan moralitas karyawan, metode yang digunakan dalam penelitian ini adalah dengan Desain penelitian dilakukan secara kuantitatif dengan teknik pengambilan sampling non probability sampling, melalui sampling purposive, Teknik analisis Regresi Linear berganda, adapun dalam penelitian ini dilakukan pengujian asumsi klasik yang terdiri dari uji reliabilitas, uji validitas, uji Normalitas, Uji Multikolinearitas, uji heteroskedasitas, Uji Autokorelasi, uji regresi partial dan uji regresi linear, jumlah sample dalam penelitian ini berjumlah 80 orang yang merupakan karyawan dari hasil penelitian diperoleh bahwa terdapat hubungan dan pengaruh antara motivasi kerja dan kinerja karyawan terhadap produktifitas kerja, dari hasil penelitian juga dinyatakan bahwa variabel motivasi kerja merupakan faktor yang dominan dan signifikan dalam menentukan produktifitas kerja., oleh sebab itu perusahaan dapat melakukan pengelolaan pemberian kompensasi, memperhatikan lingkungan kerja, kebebasan dalam memberikan Ide- ide dan gagasan baru, kebebasan dalam memberikan kritik dan saran, membangun atau meningkatkan serta kamampuan dan keahlian, peningkatan Prestasi Kerja karyawan dengan memberikan peluang atau jalan karir (path way) , mendidik kemandirian karyawan, serta memberikan kebebasan bagi karyawan untuk lebih berinovasi dan memberikan gagasan baru agar dapat meningkatkan produktifitas kerja
\end{abstract}

Kata Kunci: Motivasi, kinerja, produktivitas kerja

Abstract - Work Productivity is one of crucial purpose which give important impact for organization, and it can be described that how to increasing productivity will give good impact for organization. Work productivity can be efforted with managing the organization, based on the background the organization is able to adoptive with positive grade undergoing the process for assesing of performance, and it can be consist of motivation technic for increasing the employee morality. The method for the research use Quantitative and the method for sampling use non probability especially concern to Purposive sampling beside that the analytic data use with multiply linear regression, as for the research use the Classic assumption testing consist of reliability, validity, normality, multicollinearity, heteroskedasticity, autocorrelation, partial regression and linear regression. The amount of sample is 80, from the result of research can be described, Work motivation has relationship and impact toward employee performance and employee productivity, beside that employee motivation from the result of research can be described the employee motivation is dominance and significant factor for determining work productivity. Therefore the entreprises or company have to manage compensation, culture and environment employee, the create of new idea, give a critism and suggestion, developing and increasing capability and skill, increasing the employee prestige with giving the opportunity of path way, giving the knowledge for building employee independence to employee, eventually the employee will be innovate, and always give new idea for increasing work productivity

Keywords : motivation, performance, and work productivity

\section{PENDAHULUAN}

Peningkatan produktifitas kerja merupakan salah satu tujuan yang sangat penting bagi oragnisasi, hal ini dikarenakan dengan adanya penningkatan produktifitas akan memberikan keuntungan bagi organisasi seperti dengan adanya peningkatan produktivitas karyawan akan meningkatkan pertumbuhan profit perusahaan, dan salah satu isu terkini dalam organisassi adalah bagaimana perusahaan berupaya dalam memenuhi 
kebutuhan akan peningkatan produktivitas karyawan , dan berbagai kajian telah menganalisis bahwa dan mendiskusikan bahwa dengan adanya produktifitas dapat membawa perusahaan kearah kesuksesan, oleh sebab itu perusahaan ataupun organisasi perlu mengkaji lebih jauh lagi mengenai faktor - faktor atau kompenen utama yang dapat memberikan pengaruh terhadap peningkatan atau penurunan dalam produktivitas kerja karyawan.(Ilieska, 2013)

Beberapa literatur menyatakan bahwa upaya yang dilakukan oleh perusahaan dalam meningkatkan produktivitas merupakan suatu kunci yang dapat memberikan kontribusi dalam kesuksesan organisasi dimana keterberpihakan dari peningkatkan produktivitas dapat dilakukan dengan cara peningkatan motivasi kerja dimana, dinyatakan bahwa dalam suatu perusahaan dimana didalamnya terdapat karyawan maka diperlukannya suatu dorongan bagi keryawan dalam pencapaian tujuan organisasi sehingga dapat memberikan pengaruh dan juga dapat mencapai suatu objektivitas dalam peningkatan daya saing perusaahan, oleh sebab itu dimana upaya peningkatan motivasi karyawan yang sangat baik akan memberikan suatu optimalitas dalam performance atau produktivitas kerjanya (Omilani \& Akintolu, 2017) selain itu dalam upaya peningkatan produktifitas dan juga lingkungan perkerjaan dalam suatu organisasi pada dasarnya akan memberikan pengaruh dalam pencapaian kapabilitas individu atau kelompok dalam organisasi secara sistematis maupu permanen, dan kenyataannya bahwa pekerja yang nyaman dan memiliki kapabilitas dapat dicapai peningkatannya dengan cara memberikan suatu arahan motivasi yang tepat kerjanya (Omilani \& Akintolu, 2017)

Peningkatan produktivitas karyawan dalam upaya pengelolaan organisasi seharusnya mampu mengadopsi secara positif dari proses penilaian kinerja yang lebih baik dan juga dimana meliputi teknik motivasi untuk meningkatkan moralitas karyawan terhadap produktifitas (Kibichii, Kiptum, \& Chege, 2016)

Motivasi merupakan suatu faktor yang dapat memberikan suatu dampak terhadap psikologis serta perilaku seorang karyawan, karena dengan adanya motivasi, maka seorang karyawan akan merasa percaya diri, bersemangat dan mendapat dorongan untuk mencapai suatu tujuan. Motivasi dapat timbul dari diri sendiri ataupun orang lain, dan pada dasar nya suatu instansi bukan saja mengharapkan karyawan mau dan mampu bekerja secara giat, tetapi bagaimana memliki motivasi yang tinggi di antaranya adalah gaji atau upah, prestasi, afiliasi, kekuasaan atau karier. Dalam teori motivasi dapat membantu perusahaan dalam mendapatkan benefit yang dilihat dari modal sumber daya manusia

Motivasi juga dibutuhkan oleh karyawan dalam upaya peningkatan pengetahuan, keahlian, dan kemampuan dalam upaya meningkatakan proses kegiatan operasional pekerjaan karyawan motivasi juga merupakan suatu cara dalam pencapaian kebutuhan dalam mengaktualisasikan diri serta pembuktian dalam kemampuan karyawan untuk melaksanakan tugas yang diberikan, oleh sebab itu organisasi perlu untuk menstimulus motivasi karyawan sehingga dapat menciptakan kreativitas dan program - program yang meliputi tujuan jangka Panjang perusahaan

Faktor lainnya yang mempengaruhi peningkatan produktivitas adalah kinerja karyawan dimana kinerja karyawan ini merupakan serangkauan dari penilaian kinerja yang telah dilakukan oleh karyawan dan secara aktif dapat dinyatakan bahwa dengan adanya penilain kinerja karyawan ini dapat menjadi pedoman atau indikator bagi produktivitas yang akan mengukur pertumbuhan organisasi, dan peningkatan program kerja karyawan (Syverson, 2011), dengan melihat penilaian kinerja karyawan yang yang digunakan dalam organisasi dan dapat mempengaruhi suatu hubungan tenaga kerja dalam organisasi serta dapat mengarahkan hubungan kepada integrasi dan team work peningkatan kemampuan karyawan untuk dapat beradaptasi dalam perubahan lingkungan melalui pengembangan staf, kemampuan perencanaan dan pengembangan karir karyawan yang akhirnya dapat meningkatkan produktifitas yang lebih baik lagi (Mwema \& Gachunga, H, 2014)

Manajemen kinerja karyawan merupakan suatu proses dalam suatu perusahaan yang mana dapat menciptakan lingkungan kerja yang dapat memberikan kemampuan karyawan untuk bekerja dengan kemampuan terbaik mereka(Kibichii et al., 2016)kinerja karyawan juga meliputi suatu proses secara umum seperti penyusunan visi dan misi, review dan evaluasi kinerja, dan penghargaaan

Dalam mengatur strategi sumber daya manusia khususnya dalam meningkatkan kinerja karyawan seharusnya diintegrasikan dengan bagian dari sistem manajemen yang memiliki hubungan timbak balik, serta mengkomunikasikan kinerja tersebut kepada karyawan yang dilaporkan secara teratur dalam program kerja oleh sebab itu perusahaan ataupun organisasi harus mampu melakukan penilaian secara efesiensi sesuai dengan prosedur dan fungsi dalam meningkatkan kinerja organisasi (Kibichii et al., 2016)

Adapun penelitian yang dilakukan bertujuan untuk mengetahui pengaruh implementasi motivasi kerja dan kinerja karyawan dalam upaya peningkatan produktifitas kerja, dengan mengetahui pengaruh implementasi dari variabel independen (motivasi kerja dan kinerja karyawan) terhadap variabel dependen (produktivitas kerja), tujuan lain dalam penelitian ini juga dapat memberikan gambaran bagi perusahaan mengenai strategi yang terbaik dalam langkah menentukan produktifitas kerja
1. Hubungan antara motivasi dengan kinerja karyawan 
Pada dasarnya beberapa teori mengungkapkan bahwa dalam pengukuran dan memberikan penjelasan mengenai motivasi dalam meningkatkan kinerja karyawan yang berhubung yang menekankan pada pendekatan kinerja manajemen sumber daya manusia yang mana diasumsikan bahwa pendekatan peningkatan motibasi kerja akan meningkatkan suatu pendekatan manajemen kinerja karyawan yang akhirnya dapat meningkatkan keseluruhan kinerja organisasi(Omilani \& Akintolu, 2017)

\section{Hubungan antara kinerja karyawan dengan Produktivitas kerja}

Dalam hal pengelolaan pekerjaan beberapa faktor yang dapat dipertimbangkan menjadi kunci yang dapat memberikan pengaruh dalam keterlibatan pegawai, produktivitas, moral dan kenyamanan dimana beberapa kegiatan perusahaan melakukan beberpa pendekatan yang strategis dalam pendekatan dalam lingkungan manajemen dalam meningkatkan produktifitas melalui peningkatkan level kinerja karyawan (Sumumma, Solomon, Aule, \& Hangeior, A, 2017)

\section{Hubungan antara motivasi dengan Produktivitas kerja}

Motivasi merupakan suatu hal yang signifikan, dimana hal ini dikarenakan setiap karyawan dalam suatu organisasi akan membutuhkan pengetahuan, keahlian serta kemampuan dalam pekerjaannya, oleh karena itu jika karyawan tersebut tidak menyertakan motivasi dalam peningkatan pengetahuan, keahlian tersebut maka dapat menghasilkan performance yang kurang bagus dan begitu sebaliknya. Motivasi juga merupakan hal yang sangat krusial dalam meningkatkan produktifitas tenaga kerja dan juga dalam peningkatan layanan serta kualitas organisasi dalam upaya pencapaian tujuan organisasi , pendapat lainnya mengatakan bahwa motivasi mereupakan suatu faktor yang signifikan dalam peningkatan proses produktifitas karyawan dan kualitas pelayanan organisasi untuk mencapai tujuan organisasi (Omilani \& Akintolu, 2017)

\section{Indikator - indikator dalam motivasi kerja}

Beberapa indikator- indikator dalam motivasi kerja diantaranya:(Hamali, 2018)

1. Kebutuhan Fisiologis yang mana terdiri atas indikator pemenuhan perlindungan fisik dan pemberian kompensasi yang layak

2. Kebutuhan rasa aman yang terdiri atas pengelolaan lingkungan kerja yang aman dan nyaman, perlindungan terhadap ancaman serta perlindungan terhadap kecelakaan kerja

3. Kebutuhan sosial yang terdiri atas interaksi kelompok karyawan dengan pimpinan serta kerjasama dengan stakeholder, team work, serta membangun affiliasi

4. Kebutuhan harga diri diantaranya adalah penghormatan antara sesama rekan kerja serta penghargaan atas pekerjaan yang dilakukan

5. Aktualisasi diri diantaranya pengembangan kemampuasn karyawan, pengembangan keahlian karyawan, dan potensi karyawan , pemberian kebebasan dalam memberikan ide - ide serta gagasan baru, serta memberikan masukan serta kritikan bagi kemajuan organisasi

5. Indikator - indikator dalam produktifitas kerja diantaranya

Beberapa indikator - indikator dalam produktifitas kerja diantaranya : (Sutrisno, 2016)

1. Kemampuan dimana terdiri atas indikator sebagai berikut: kemampuan karyawan dalam melaksanakan tugas, professionalisme dan etos kerja

2. Peningkatan hasil dengan indikator diantaranya peningkatan kuantitas dan kualitas kerja, dan peningkatan prestasi kerja

3. Semangat kerja dengan indikator etos kerja

4. Mutu dengan indikator peningkatan mutu dan kualitas kerja

5. Efisiensi dengan indikator pemanfaat fasilitas sarana dan prasarana dalam bekerja , penggunaan sumber daya bahan baku (sumber daya produksi) yang berkualitas tinggi)

6. Indikator -indikator dalam Kinerja Karyawan beberapa diantaranya (Wijaya \& Andreani, 2015)

1. Kuantitas pekerjaan yang mana terdiri dari indikator diantaranya bekerja sesuai dengan kamampuan dan keahlian, meningkatkan produktifitas kerja

2. Kualitas pekerjaan terdiri dari indikator peningkatan prestasi kerja serta penggunaan fasilitas dalam menunjang pekerjaan

3. Kemandirian dengan indikator kemampuan dalam bekerja secara mandiri, komitmen karyawan

4. Inisiatif yang terdiri dari kemandirian, fleksibilitas inisiatif, tanggung jawab, beradaptasi terhadap perubahan

5. Adaptabilitas yang terdiri dari kemampuan beradaptasi dengan lingkungan pekerjaan

6. Kerjasama yang terdiri dari kerjasama dengan pihak lain atau stakeholder

Adapun kerangka pemikiran dalam penelitian ini adalah : 


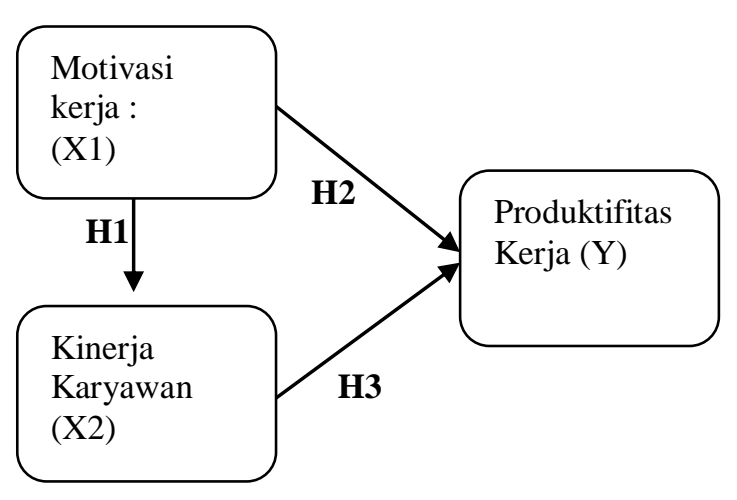

Gambar 1: Kerangka Pemikiran

Dari kerangka pemikiran diatas maka dapat diambil hipotesis:

1. Ho: Tidak terdapat pengaruh dan hubungan antara Motivasi kerja dan kinerja karyawan H1: Terdapat pengaruh dan hubungan antara motivasi kerja dan kinerja karyawan

2. Ho: Tidak terdapat pengaruh dan hubungan antara Motivasi kerja dan produktifitas kerja

$\mathrm{H} 2$ : Terdapat pengaruh dan hubungan antara motivasi kerja dan produktifitas kerja

3. Ho: Tidak terdapat pengaruh dan hubungan antara kinerja karyawan terhadapat produktifitas kerja

$\mathrm{H} 2$ : Terdapat pengaruh dan hubungan antara kinerja karyawan terhadapat produktifitas kerja

\section{METODOLOGI PENELITIAN}

Desain penelitian dilakukan secara kuantitatif dengan teknik pengambilan sampling non probability sampling yang meliputi teknik penentuan sample melalui sampling purposive, jumlah sample dalam penelitian ini berjumlah 80 orang yang merupakan karyawan pada bagian Line G PT Xacti Indonesia Kota Depok, adapun karakteristik responden dalam penelitian ini terdiri atas jenis kelamin, usia, pendidikan, masa kerja. Adapun data yang didapatkan berupa data primer yakni dari penyebaran kuesioner kemudian diolah dengan menggunakan program aplikasi SPSS(Statistical Package For The Social Sciences) dengan Teknik analisis Regresi Linear berganda, adapun dalam penelitian ini dilakukan pengujian asumsi klasik yang terdiri dari uji reliabilitas, uji validitas, uji Normalitas, Uji Multikolinearitas, uji heteroskedasitas, Uji Autokorelasi, uji regresi partial dan uji regresi linear

\section{HASIL DAN PEMBAHASAN}

Dari hasil penelitian yang diperoleh maka dapat dijelaskan sebagai berikut : variabel motivasi kerja, kinerja karyawan dan produktifitas kerja:

Tabel 1. Pengujian Reliabilitas

\begin{tabular}{|l|l|l|}
\hline No & Variabel & $\begin{array}{l}\text { Nilai } \\
\text { Cronbach } \\
\text { Alfa }\end{array}$ \\
\hline 1 & Motivasi Kerja & 0,850 \\
\hline 2 & Kinerja Karyawan & 0,903 \\
\hline 3 & Produktivitas Kerja & 0,874 \\
\hline
\end{tabular}

Sumber : Pengolahan data 2019

Dari hasil Uji reliabilitas diatas diperoleh suatu nilai cronbach's alfa diantaranya motivasi kerja, kinerja karyawan sebesar 0,903 dan Produktifitas kerja sebesar 0,874 dimana bahwa jika suatu variabel berada diantara nilai Cronbach alfa sebesar 0,60 maka dapat dinyatakan bahwa variabel diatas dikatakan reliabel, dari hasil penelitian diatas untuk ketiga variabel tersebut dinyatakan reliabel.(Widarjono, 2015)

\section{Uji Validitas}

2.1 Uji Validitas Produktifitas Kerja Adapun hasil uji validitas dari indikator - indikator untuk ketiga variabel yang diteliti dinyatakan sebagai berikut:

Tabel 2. Validitas Produktifitas Kerja

\begin{tabular}{|c|c|c|c|c|}
\hline No & Indikator & $\begin{array}{l}\text { Nilai R } \\
\text { hitung }\end{array}$ & $\begin{array}{l}\mathrm{R} \\
\text { tabel }\end{array}$ & Keterangan \\
\hline 1 & $\begin{array}{l}\text { Pelaksanaan } \\
\text { Tugas }\end{array}$ & 0,669 & \multirow[t]{9}{*}{0,219} & Valid \\
\hline 2 & Profesionalisme & 0,698 & & Valid \\
\hline 3 & $\begin{array}{l}\text { Peningkatan } \\
\text { Prestasi Kerja }\end{array}$ & 0,652 & & Valid \\
\hline 4 & $\begin{array}{l}\text { Team Work - } \\
\text { Kerjasama }\end{array}$ & 0,588 & & Valid \\
\hline 5 & Etos Kerja & 0,599 & & Valid \\
\hline 6 & $\begin{array}{l}\text { Peningkatan } \\
\text { Kemampuan } \\
\text { Kerja }\end{array}$ & 0,731 & & Valid \\
\hline 7 & $\begin{array}{l}\text { Pengambilan } \\
\text { Resiko }\end{array}$ & 0,337 & & Valid \\
\hline 8 & $\begin{array}{l}\text { Peningkatan } \\
\text { Mutu dan } \\
\text { Kualitas } \\
\text { Pekerjaan } \\
\end{array}$ & 0,654 & & Valid \\
\hline 9 & \begin{tabular}{ll}
\multicolumn{2}{l}{ Pemanfaatan } \\
Fasilitas atau \\
sarana \\
prasarana
\end{tabular} & 0,602 & & Valid \\
\hline
\end{tabular}

1. Uji Reliabilitas

Berikut ditampilkan hasil uji reliabiltas dari 


\begin{tabular}{|l|l|l|l|l|}
\hline 10 & $\begin{array}{l}\text { Pemanfaatan } \\
\text { Sumber Daya } \\
\text { perusahaan } \\
\text { yang }\end{array}$ & 0,698 & & Valid \\
& $\begin{array}{l}\text { Berkualitas } \\
\text { Tinggi }\end{array}$ & & & \\
\hline
\end{tabular}

Sumber : Pengolahan data (2019)

Dari hasil pengolahan data diatas dimana nilai validitas dilihat dari nilai $\mathrm{R}$ hitung atau nilai corrected item total correlation dimana apabila nilai R hitung > Rtabel (df : N-2, 5\% ) dapat diartikan bahwa maka indikator tersebut dinyatakan valid, dari data pengolahan dengan nilai tabel validitas maka disimpulkan bahwa nilai Rtabel sebesar : 0,291 dibandingkan nilai R Hitung yang berada diatas nilai $\mathrm{R}$ tabel maka dapat dinyatakan untuk keseluruhan indikator Variabel produktifitas kerja dapat dikatakan valid karena nilai Rhitung > Rtabel.(Widarjono, 2015)

2.2 Uji Validitas Kinerja Karyawan

Hasil Uji Validitas kinerja karyawan dapat dinyatakan sebagai berikut :

Tabel 3. Validitas Kinerja Karyawan

\begin{tabular}{|c|c|c|c|c|}
\hline No & Indikator & $\begin{array}{c}\text { Nilai } \\
\mathrm{R} \\
\text { hitung }\end{array}$ & $\begin{array}{l}\mathrm{R} \\
\text { tabel }\end{array}$ & Keterangan \\
\hline 1 & $\begin{array}{l}\text { Pekerjaan } \\
\text { sesuai dengan } \\
\text { kamampuan } \\
\text { dan keahlian }\end{array}$ & 0,538 & \multirow{11}{*}{0,219} & valid \\
\hline 2 & $\begin{array}{l}\text { Peningkatan } \\
\text { Produktifitas }\end{array}$ & 0,697 & & valid \\
\hline 3 & $\begin{array}{l}\text { Peningkatan } \\
\text { Prestasi Kerja }\end{array}$ & 0,563 & & valid \\
\hline 4 & $\begin{array}{l}\text { Fasilitas } \\
\text { Penunjang } \\
\text { Pekerjaan }\end{array}$ & 0,683 & & valid \\
\hline 5 & $\begin{array}{l}\text { Bekerja Secara } \\
\text { Mandiri }\end{array}$ & 0,68 & & valid \\
\hline 6 & $\begin{array}{l}\text { Komitmen } \\
\text { Dalam Bekerja }\end{array}$ & 0,711 & & valid \\
\hline 7 & $\begin{array}{l}\text { Fleksible, } \\
\text { kemandirian, } \\
\text { Inovasi dan } \\
\text { gagasan baru }\end{array}$ & 0,560 & & valid \\
\hline 8 & $\begin{array}{l}\text { Bertanggung } \\
\text { Jawab Dalam } \\
\text { Bekerja }\end{array}$ & 0,643 & & valid \\
\hline 9 & $\begin{array}{l}\text { Beradaptasi } \\
\text { dengan } \\
\text { lingkugan kerja }\end{array}$ & 0,651 & & valid \\
\hline 10 & Perubahan & 0,771 & & valid \\
\hline 11 & Tim Kerja & 0,756 & & valid \\
\hline
\end{tabular}

Sumber : Pengolahan data (2019)
Berdasarkan hasil pengolahan data untuk uji validitas diatas dimana digambarkan bahwa nilai $\mathrm{R}$ tabel 0,219 dan nilai $\mathrm{R}$ tabel berada diatas range rata - rata untuk setiap indikator diantaranya : diatas 0,50 maka dapat diartikan juga bahwa nilai Rhitung > Rtabel maka untuk setiap indikator dari variabel diatas dikatakan valid

\subsection{Uji Validitas Motivasi Kerja}

Uji validitas motivasi kerja dapat dijelaskan sebagai berikut :

Tabel 4.Uji Validitas untuk Motivasi Kerja

\begin{tabular}{|c|c|c|c|c|}
\hline & Indikator & $\begin{array}{l}\text { Nilai } \\
\mathrm{R} \\
\text { hitung }\end{array}$ & $\begin{array}{l}\mathrm{R} \\
\text { tabel }\end{array}$ & Keterangan \\
\hline 1 & $\begin{array}{l}\text { Perlindungan } \\
\text { Fisik }\end{array}$ & 0,513 & \multirow[t]{10}{*}{0,219} & valid \\
\hline 2 & Kompensasi & 0,470 & & valid \\
\hline 3 & $\begin{array}{l}\text { Lingkungan } \\
\text { Kerja }\end{array}$ & 0,596 & & valid \\
\hline 4 & $\begin{array}{l}\text { Keamanan } \\
\text { kerja }\end{array}$ & 0,648 & & valid \\
\hline 5 & $\begin{array}{l}\text { Interaksi } \\
\text { dengan } \\
\text { stakeholder }\end{array}$ & 0,653 & & valid \\
\hline 6 & $\begin{array}{l}\text { Kerjasama } \\
\text { dan Affiliasi }\end{array}$ & 0,707 & & valid \\
\hline 7 & $\begin{array}{l}\text { Penghormatan } \\
\text { dan } \\
\text { penghargaan }\end{array}$ & 0,651 & & valid \\
\hline 8 & $\begin{array}{l}\text { Pengembagan } \\
\text { Kemampuan, } \\
\text { skill dan } \\
\text { Potensi }\end{array}$ & 0,606 & & valid \\
\hline 9 & $\begin{array}{l}\text { Ide- ide dan } \\
\text { gagasan baru }\end{array}$ & 0,474 & & valid \\
\hline 10 & $\begin{array}{l}\text { kritikan dan } \\
\text { saran }\end{array}$ & 0,448 & & valid \\
\hline
\end{tabular}

Sumber : Pengolahan Data 2019

Begitu juga halnya untuk hasil pengolahan data dimana nilai Rtabel sebesar : 0,219 dan nilai Rtabel dengan range nilai $0,448-0,707$ dan dapat diartikan Bahwa nilai $\mathrm{R}$ tabel lebih kecil dari nilai $\mathrm{R}$ hitung, maka dapat dinyatakan bahwa indikator dari setiap variabel dinyatakan valid

3. Pengujian Asumsi Klasik

3.1 Uji Normalitas

Tabel 5 : One-Sample Kolmogorov-Smirnov Test

\begin{tabular}{|l|l|r|}
\hline \multicolumn{2}{|l|}{} & $\begin{array}{c}\text { Unstandardiz } \\
\text { ed Residual }\end{array}$ \\
\hline $\mathrm{N}$ & 80 \\
\hline \multirow{2}{*}{ Normal Parameters ${ }^{a, b}$} & $\begin{array}{l}\text { Mean } \\
\text { Std. } \\
\text { Deviation }\end{array}$ & 2,21018381 \\
\hline Most Extreme & Absolute &, 150 \\
\hline
\end{tabular}




\begin{tabular}{|l|l|r|}
\hline Differences & Positive &, 127 \\
\cline { 2 - 3 } & Negative &,- 150 \\
\hline Test Statistic &, 150 \\
\hline Asymp. Sig. (2-tailed) &, $000^{\mathrm{c}}$ \\
\hline
\end{tabular}

a. Test distribution is Normal.

b. Calculated from data.

c. Lilliefors Significance Correction.

Dari data tabel One - Sample Kolmoggorov Smirnov Test dengan nilai Asymp Sig (2-tailed) yang berada < nilai $p$-value yakni 0,005 dapat dinyatakan bahwa data tersebut terdistribusi tidak normal yang dapat dimaknai bahwa data yang dimiliki memiliki variasi atau keragaman nilai atau karakteristik sample

\subsection{Uji Multikolinearitas dengan menggunakan Uji} Korelasi

Adapun pengujian dengan mendeteksi multikolinearitas ini didasarkan atas korelasin linear antara variabel bebas dalam suatu regresi, adapun untuk hasil uji multikolinearitas dapat dijabarkan sebagai berikut:

Tabel 6 : Uji Multikolinearitas dengan Korelasi Spearman Correlations

\begin{tabular}{|c|c|c|c|c|c|}
\hline & $\begin{array}{c}\text { Unsta } \\
\text { ndardi } \\
\text { zed } \\
\text { Resid } \\
\text { ual } \\
\end{array}$ & $\mathrm{X} 1$ & $\mathrm{X} 2$ \\
\hline \multirow[t]{9}{*}{$\begin{array}{l}\text { Spearma } \\
\text { n's rho }\end{array}$} & \multirow[t]{3}{*}{$\begin{array}{l}\text { Unstan } \\
\text { ardized } \\
\text { esidual }\end{array}$} & $\begin{array}{l}\text { Correl } \\
\text { ation } \\
\text { Coeffi } \\
\text { cient }\end{array}$ & 1,000 & 078 & 047 \\
\hline & & $\begin{array}{l}\text { ig. (2- } \\
\text { tailed) }\end{array}$ & & ,494 & 679 \\
\hline & & $\mathrm{N}$ & 80 & 80 & 80 \\
\hline & \multirow[t]{3}{*}{$\mathrm{X} 1$} & $\begin{array}{l}\text { Correl } \\
\text { ation } \\
\text { Coeffi } \\
\text { cient }\end{array}$ & ,078 & 1,000 & ,645* \\
\hline & & $\begin{array}{l}\text { Sig. } \\
(2- \\
\text { tailed) }\end{array}$ & ,494 & . & ,000 \\
\hline & & $\mathrm{N}$ & 80 & 80 & 80 \\
\hline & \multirow[t]{3}{*}{$\mathrm{X} 2$} & $\begin{array}{l}\text { Correl } \\
\text { ation } \\
\text { Coeffi } \\
\text { cient }\end{array}$ &, 047 &, $645^{*}$ & $\begin{array}{l}1,00 \\
0\end{array}$ \\
\hline & & $\begin{array}{l}\text { Sig. } \\
(2- \\
\text { tailed })\end{array}$ & ,679 &, 000 & . \\
\hline & & $\mathrm{N}$ & 80 & 80 & 80 \\
\hline
\end{tabular}

**. Correlation is significant at the 0.01 level (2tailed).

Sumber : Pengolahan Data 2019

Dalam asumsi uji multikolinearitas dimana Rule of Thumb dari pengujian ini adalah jika koefisien korelasi berada diatas 0,85 maka diduga terjadinya multikolinearitas, namun jika korelasi berada di bawah 0,85 maka tidak mengandung unsur Multikolinearitas (Widarjono, 2015)

Dari data diatas dapat disimpulkan bahwa besarnya nilai Correlation Coefisien diantara variabel independent yakni motivasi kerja dan kinerja karyawan berada dibawah nilai 0,85 yakni dapat dinyatakan bahwa tidak terdapat unsur multikolinearitas dalam model diatas

\subsection{Uji Heteroskedastisitas}

Dimana merupakan varian variabel ganguan yang tidak konstan, adaun salah satu cara dalam mendeteksi heteroskedasitas ini dapat menggunakan UJI Korelasi Spearman dimana dalam pengujian ini jika nilai t hitung lebih kecil dari pada $t$ kritis maka tidak adanya heteroskedasitas namun apabila nilai $\mathrm{t}$ hitung lebih besar dari pada nilai t kritis maka terjadinya heteroskedasitas :

$$
\mathrm{T}: \frac{\mathrm{rs}(\sqrt{\mathrm{n}}-2)}{\sqrt{1-\mathrm{rs}^{2}}}
$$

Dari nilai t kritis yang diperoleh sebesar 1,99 (df : n$2,5 \%$ ) dan nilai t hitung untuk variabel motivasi kerja sebesar 0,691 maka dapat diartikan bahwa nilai t kritis lebih besar daripada t kritis (1,99>0,691, begitu juga dengan nilai Thitung dari variabel kinerja karyawan dimana sebesar 0,689 dan nilai $\mathrm{T}$ kritis sebesar 1,99 sehingga $\mathrm{T}$ kritis lebih besar dari Thitung ,dari hasil tersebut dapat dinyatakan bahwa tidak adanya heteroskedasitas untuk model tersebut (Sugiyono, 2013)

\subsection{Uji Autokorelasi}

Merupakan hubungan antara variabel ganguan suatu observasi dengan variabel ganguan observasi lain, uji autokorelasi ini dapat dilakukan dengan menggunakan metode Durbin - Watson (DW) dimana dalam metode Durbin Watson dimana dalam metode Durbin - Watson ini jika nilai d mendekati 2 maka tidak terjadi autokorelasi, namun jika nilai d mendekati nilai 0 atau mendekati nilai 4 maka diduga terjadi autokorelasi positif atau autokorelasi negatif, berikut diitampilkan nilai Durbin - Watson

Tabel 7: Model Summary ${ }^{\mathrm{b}}$

\begin{tabular}{|c|c|c|c|c|c|c|}
\hline & \multicolumn{5}{|c|}{ Change Statistics } & \\
\hline Model & $\begin{array}{l}\text { R } \\
\text { Square } \\
\text { Change }\end{array}$ & F Change & df1 & df2 & $\begin{array}{l}\text { Sig. F } \\
\text { Change }\end{array}$ & $\begin{array}{l}\text { Durbin } \\
\text { Watson }\end{array}$ \\
\hline 1 & $609^{a}$ & 60,006 & 2 & 77 &, 000 & 1,895 \\
\hline
\end{tabular}

a. Predictors: (Constant), X2, X1

b. Dependent Variable: Y

Dari data tabel Model summary diatas dapat di gambarkan bahwa nilai dl dan du dimana nilai du dan dl : $\alpha: 5 \%$ dan $\mathrm{n}=80$ dan $\mathrm{K}: 2$ dimana nilai $\mathrm{dl}$ : 1,611 dan nilai du : 1,662, dan nilai persyaratan untuk uji autokorelasi adalah jika du<2<4-du maka nilai yang diperoleh adalah : 1,662 < $2<2,338$ 
diartikan bahwa pada model ini tidak terjadi autokorelasi

\subsection{Uji Regresi Partial}

Dalam regresi partial ini dimana menganalisis antara korelasi variabel dependen dimana adalah variabel motivasi kerja (X1) dan variabel kinerja karyawan (X2) terhadap variabel independent yakni Produktifitas kerja (Y1) dari data pengolahan diatas diperoleh nilai sebagai berikut:

Tabel 8. Correlations

\begin{tabular}{|l|l|l|l|l|}
\hline \multicolumn{2}{|c|}{} & $\begin{array}{c}\text { Produk } \\
\text { tifitas } \\
\text { Kerja } \\
\text { (Y) }\end{array}$ & $\begin{array}{c}\text { Motivasi } \\
\text { Kerja } \\
\text { (X1) }\end{array}$ & $\begin{array}{l}\text { Kinerja } \\
\text { Karyaw } \\
\text { an (X2) }\end{array}$ \\
\hline $\begin{array}{l}\text { Pearson } \\
\text { Correlati } \\
\text { on }\end{array}$ & $\begin{array}{l}\text { Produktifi } \\
\text { tas Kerja } \\
\text { (Y) }\end{array}$ & 1,000 &, 740 &, 683 \\
\cline { 2 - 5 } & $\begin{array}{l}\text { Motivasi } \\
\text { Kerja } \\
\text { (X1) }\end{array}$ &, 740 & 1,000 &, 676 \\
\cline { 2 - 5 } & $\begin{array}{l}\text { Kinerja } \\
\text { Karyawan } \\
\text { (X2) }\end{array}$ &, 683 &, 676 & 1,000 \\
\hline $\begin{array}{l}\text { Sig. (1- } \\
\text { tailed) }\end{array}$ & $\begin{array}{l}\text { Produktifi } \\
\text { tas Kerja } \\
\text { (Y) }\end{array}$ &. &, 000 &, 000 \\
\cline { 2 - 5 } & $\begin{array}{l}\text { Motivasi } \\
\text { Kerja } \\
\text { (X1) }\end{array}$ &, 000 &. &, 000 \\
\hline $\begin{array}{l}\text { Kinerja } \\
\text { Karyawan } \\
\text { (X2) }\end{array}$ &, 000 &, 000 &. \\
\hline
\end{tabular}

Sumber : Pengolahan data 2019

Dari data Coefficient diperoleh nilai coefficient sebesar 0,740 antara variabel produktifitas kerja terhadap motivasi kerja yang dapat dimaknai memiliki tingkat hubungan yang kuat berdasarkan interpretasi korelasi, begitu juga halnya antara variabel produktifitas kerja terhadap kinerja karyawan sebesar 0,683 yang juga dapat diartikan bahwa memiliki hubungan yang kuat, jika dilihat nilai coefficient antara variabel dependen motivasi kerja dan kinerja karyawan sebesar 0,676 yang dapat dinyatakan bahwa antara variabel bebas tersebut juga memiliki hubungan yang kuat dan positif, maka dapat diambil suatu kesimpulan dari hipotesis sebagai berikut :

1. H1 : Terdapat hubungan antara motivasi kerja terhadap kinerja karyawan

Dari data diatas diperoleh nilai pearson correlation pada tabel Correlation untuk motivasi kerja terhadap kinerja karyawan sebesar 0,676 sehingga dapat disimpulkan bahwa terdapat hubungan yang kuat antara motivasi kerja dan kinerja karyawan

2. H2 : Terdapat hubungan antara motivasi kerja terhadap Produktifitas kerja

Dari data diatas juga dapat disimpulkan bahwa nilai pearson correlation antara motivasi kerja dan produktivitas sebesar 0,740 yang mana dapat diartikan bahwa motivasi kerja memiliki hubungan yang cukup kuat dengan produktifitas kerja

3.H3 : Terdapat hubungan antara kinerja karyawan terhadap Produktifitas kerja

Begitu juga halnya hubungan antara kinerja karyawan dan produktifitas kerja dimana nilai correlation sebesar 0,683 dan dapat disimpulkan bahwa dari data diatas antara kinerja karywan dan produktifitas kerja memiliki hubungan yang kuat

\subsection{Uji Regresi Berganda}

Merupakan suatu Analisa dari hubungan serta pengaruh antara variabel independent dan variabel dependen yang lebih dari satu predictor, dari pengolahan data untuk hasil uji regresi berganda dapat digambarkan sebagai berikut:

Tabel 9 : Coefficients ${ }^{\mathrm{a}}$

\begin{tabular}{|c|c|c|c|c|c|}
\hline \multirow[b]{2}{*}{ Model } & \multicolumn{3}{|c|}{\begin{tabular}{|l|l|} 
Unstandardi & $\begin{array}{l}\text { Standa } \\
\text { rdized }\end{array}$ \\
zed & Coeffi \\
Coefficients & cients \\
\end{tabular}} & \multirow[b]{2}{*}{ t } & \multirow[b]{2}{*}{ Sig. } \\
\hline & B & \begin{tabular}{|l|} 
Std. \\
Error
\end{tabular} & Beta & & \\
\hline \begin{tabular}{|l|l}
1 & (Constant) \\
\end{tabular} & \multicolumn{2}{|c|}{$1,4554,129$} & &, 352 &, 725 \\
\hline \begin{tabular}{|l} 
Motivasi \\
Kerja (X1)
\end{tabular} &, 601 &, 113 &, 512 & 5,295 &, 000 \\
\hline $\begin{array}{l}\text { Kinerja } \\
\text { Karyawan } \\
(\mathrm{X} 2)\end{array}$ &, 321 &, 092 &, 337 & 3,481 &, 001 \\
\hline
\end{tabular}

a. Dependent Variable: Produktifitas Kerja (Y)

Sumber : Pengolahan data 2019

Dari tabel coefficient diatas maka dapat diperoleh persamaan regresi sebagai berikut:

$$
\mathrm{Y}: 0,61 \mathrm{X} 1+0,321 \mathrm{X} 2+\mathrm{e}
$$

Dimana disini $\mathrm{Y}$ merupakan variabel dependen yakni produktifitas kerja, variabel X1 merupakan motivasi kerja dan X2 merupakan variabel kinerja karyawan. Dari data diatas dapat dianalisa bahwa dimana motivasi kerja memiliki hubungan yang positif dan searah dengan peningkatan produktifitas kerja, yakni sebesar 0,61, begitu juga dengan kinerja karyawan memiliki hubungan yang positif dan searah sebesar 0,321, dari data tersebut dengan menggunakan perumpamaan satuan angka bagi variabel motivasi kerja dan produktifitas kerja maka variabel motivasi kerja memberikan dampak pengaruh yang cukup besar dibandingkan dengan kinerja karyawan

Beberapa literatur yang menyatakan bahwa terdapat hubungan antara motivasi kerja dengan kinerja karyawan begitupula halnya antara kinerja karyawan dengan produktifitas kerja, namun pada dasarnya dari hasil penelitian ini hanya membatasi pada ruang lingkup responden pada bagian Line G PT Xacti Indonesia Kota Depok, oleh sebab itu dan dilakukan pengujian pada ketiga variabel diatas, sehingga hasil penelitian ini tidak dapat di generalisasi untuk semua 
responden dan untuk permasalahan diatas.

\section{KESIMPULAN}

Dari hasil dan pembahasan diatas maka dapat diperoleh suatu kesimpulan sebagai berikut : dari nilai coefficient terhadap uji regresi linear dapat dinyatakan bahwa variabel motivasi kerja merupakan faktor yang dominan dan signifikan dalam menentukan produktifitas kerja, oleh sebab itu perusahaan perlu memberikan perhatian lebih terhadap motivasi kerja seperti halnya dalam pemberian kompensasi, memperhatikan lingkungan kerja, kebebasan dalam memberikan Ide- ide dan gagasan baru, kebebasan dalam memberikan kritik dan saran

Selain motivasi kerja diatas yang merupakan faktor yang sangat signifikan dalam peningkatan produktifitas kerja, hal yang perlu diperhatikan kembali oleh perusahaan adalah bagaimana meningkatkan produktifitas kinerja karyawan melalui dengan membangun atau meningkatkan serta memperhatikan kamampuan dan keahlian terhadap pekerjaan yang dibebankan kepada karyawan, peningkatan Prestasi Kerja karyawan dengan memberikan peluang atau jalan karir (path way) bagi karyawan, selain itu perusahaan juga sebaiknya lebih fleksible, berupaya mendidik kemandirian karyawan, serta memberikan kebebasan bagi karyawan untuk lebih berinovasi dan memberikan gagasan baru agar dapat meningkatkan produktifitas kerja

\section{REFERENSI}

Hamali, A. Y. (2018). Pemahaman Manajemen Sumber Daya Manusia Strategi Mengelola Karyawan. Yogyakarta: CAPS (Center for Academic Publishing Service).

Ilieska, K. (2013). Customer Satisfaction Index - as a Base for Strategic Marketing Management. Strategic Marketing Management,TEM Journal, 2(4), 327-331.

Kibichii, K. E., Kiptum, K. G., \& Chege, P. K. (2016). Effects of Performance Management
Process on Employee Productivity: A Survey of Commercial Banks in Turkana County. IOSR Journal of Business and Management (IOSR-JBM), 18(11), 52-64. https://doi.org/10.9790/487X-1811045264

Mwema, W. N., \& Gachunga, H, G. (2014). The Influence Of Performance Appraisal On Employee Productivity In Organizations: A Case Study Of Selected Who Offices In East Africa. International Journal of Social Sciences and Entrepreneurship, 1(11), 1-13.

Omilani, M., \& Akintolu, M. (2017). The Effectiveness of Motivational Strategies on Productivity in Selected Financial Institutions in Nigeria. American Journal of Industrial and Business Management, 881-892. https://doi.org/10.4236/ajibm.2017.77062

Sugiyono. (2013). Metode Penelitian Kuantitatif, Kualitatif dan Kombinasi (Mixed Methods). Bandung: Penerbit Alfabeta Bandung.

Sumumma, Solomon, Z., Aule, O., \& Hangeior, A, A. (2017). Performance Appraisal and Employee Productivity in Plateau State Internal Revenue Service, Nigeria. Journal of Public Administration and Governance, 7(4), 24-37.

https://doi.org/10.5296/jpag.v7i4.11973

Sutrisno, E. (2016). Metode Penelitian Kuantitatif, Kualitatif, dan R\&D. Bandung: Alfabeta, CV.

Syverson, C. (2011). What Determines Productivity? Journal of Economic Literature, 49(2), 326-365.

Widarjono, A. (2015). Analisis Multivariat Terapan dengan Program SPSS, AMOS, dan SMARTPLS Edisi Kedua. Yogyakarta: UPP STIM YKPN.

Wijaya, T., \& Andreani, F. (2015). Pengaruh Motivasi Dan Kompensasi Terhadap Karyawan Pada Pt Sinar Jaya Abadi Bersama. Agora, 3(2). 